\title{
Qualitative analysis of attitudes, behaviors, and demands of vulnerable men in Tehran, Iran
}

\author{
Minoo Mohraz ${ }^{1}$, SeyedAhmad SeyedAlinaghi ${ }^{1}$, Ali Asadollahi-Amin ${ }^{1}$, Rahele Golrokhi ${ }^{1}$, \\ Effat Merghati Khoei ${ }^{2}$, Habib Yousefi², Salar Pashangzadeh ${ }^{1}$, Omid Dadras ${ }^{3}$
}

${ }^{1}$ Iranian Research Center for HIV/AIDS, Iranian Institute for Reduction of High-Risk Behaviors, Tehran University of Medical Sciences, Tehran, Iran

${ }^{2}$ Iranian National Center for Addiction Studies, Tehran University of Medical Sciences, Tehran, Iran

${ }^{3}$ The Excellent Center for Dengue and Community Public Health (EC for DACH), School of Public Health, Walailak University, Nakhon Si Thammarat, Thailand

\begin{abstract}
Introduction: Men who have sex with men (MSM) are a vulnerable group, and their psychological, physical, and social well-being could be affected by various factors. They are also at higher risk of HIV and other sexually transmitted infections (STIs). This study was conducted to identify socio-demographic characteristics and HIV-related risk behaviors among MSM in Iran.

Material and methods: A qualitative study was conducted among MSM attending a sexual health clinic in a referral hospital, in Tehran in 2018. Data was collected through four focus group discussions. Content analysis approach was used in data analysis.

Results: One hundred MSM were enrolled in this study. Majority of them were 18-25 years old. Participants had numerous comments about their sexual identity and orientation; some were confused about it and mentioned stigma, discrimination, and lack of social and legal support as the most important contributing factors. Social media and parties were the most common places to find a partner. Moreover, majority had a negative attitude toward emotional attachment and marriage in sexual minorities; this was attributed to partner's infidelity, low commitment, and lack of family support by some participants.

Conclusions: MSM is a vulnerable to psychosocial problems group due to low sexual knowledge and lack of community and legal supports. Data also indicated high probability of HIV transmission among this group because of risky sexual behaviors.
\end{abstract}

HIV AIDS Rev 2021; 20, 4: 302-310

DOI: https://doi.org/10.5114/hivar.2021.111971

Key words: men who have sex with men, MSM, sexual identity, sexual risk behavior, HIV transmission, HIV prevention.

\section{Introduction}

Stigmatized sexual minority groups, such as men who have sex with men (MSM), are exposed to a wide variety of

Address for correspondence: Prof. Minoo Mohraz, Iranian Research Center for HIV/AIDS, Iranian Institute for Reduction of High-Risk Behaviors, Tehran University of Medical Sciences, Tehran, Iran, e-mail: minoomohraz@gmail.com

stressors that can affect their psychological, physical, and social well-being $[1,2]$. These stressors include abuse, violence, homophobia, and discrimination, collectively called 'minority group stress', and could predispose them to poor

Article history:

Received: 25.12.2020

Received in revised form: 28.03.2021

Accepted: 04.04.2021

Available online: 30.11 .2021
International Journal of HIV-Related Problems

HIV \& AIDS R e v i e w 
mental health and human immunodeficiency virus (HIV) infection $[3,4]$.

In the United States, significantly higher rates of lifetime mood and anxiety disorders have been reported among MSM compared to general population $[5,6]$. Psychological problems are highly associated with drug abuse and risky sexual behavior in these people $[3,7]$. This could expose them to a greater risk for HIV infection due to higher prevalence of sexual contacts, multiple partnerships, and sexual abuse $[8,9]$. The evidence has shown a link between drug abuse and risky health behaviors, especially among MSM [10-13].

MSM is one of the most vulnerable groups for acquiring HIV infection and other sexually transmitted infections (STIs) worldwide [14-16]. They still constitute the largest group of newly diagnosed HIV infections in countries, such as Germany. Furthermore, they are at a higher risk of mental health problems and drug abuse $[17,18]$. The main reasons include internalized homo-negativity (concealment of their own identity, fear of disapproval), negative self-concept, and life experiences of discrimination and violence [18-22]. MSM experience intense social and psychological pressures, such as prejudice-based discrimination, physical and verbal violence, and internalized homo-negativity. Drug abuse can also be expected due to dysfunctional coping mechanisms and increased minority stress $[1,23,24]$.

MSM is also a high-risk group of HIV acquisition in Iran. To date, little is known regarding the behavioral, social, and psychological characteristics of this vulnerable population in Iran, in which implementation of preventive and therapeutic strategies for this high-risk population is extremely difficult. This study aimed to explore socio-demographic and psychological features as well as HIV-related risk behaviors among MSM in Iran.

\section{Materials and methods}

This was a qualitative study, which was designed to identify and describe attitudes, experiences, behaviors, and demands of MSM in Iran. Inclusion criteria were age of more than 16 years, ability to read and write, and consent to participate in the study. Four focus group discussions (FGDs) were conducted for data collection in sexual health clinic of a referral hospital in Tehran, Iran, in 2018.

\section{Data collection}

Data comprised participants' statements, gathered through FGDs based on the study objectives. With all participants' written consent obtained, interviews were recorded at each session using a voice recorder. Furthermore, participants' interactions, such as agreement or disagreement on particular topics, facial or verbal expression, were recorded and included in data analysis. Whenever necessary, probe questions were asked to explore respondent's in-depth beliefs and attitude on a particular topic. Each FGD lasted about 90 to 120 minutes. All recorded interviews were transcribed into texts by the researchers.

\section{Data analysis}

We used a content analysis approach in data analysis, which investigated a number, order, and impact of words and sentences stated by participants to recognize the main concepts and themes. After multiple and careful reading of FGDs' transcripts, key codes and statements were extracted, with similar codes grouped as categories and main themes built combining similar categories. Demographic information were also collected through a sexual health screening questionnaire and described as numbers and proportions.

\section{Ethical considerations}

The protocol of this study was reviewed and approved by the Institutional Review Board (IRB) of Iran's Ministry of Health and Medical Education (MOH\&ME). Both verbal and written consents were obtained from all participants. The participants were assured about confidentiality and anonymity of their information and were informed about their right to withdraw from the study at any time. Interviews were recorded with a prior permission from participants. Each participant was assigned a code and was called by that code during the interview to ensure anonymity. Interviews' voices and transcripts were secured on the principal researcher's laptop, and only authorized persons could access the data through a password provided by the principal researcher.

\section{Results}

\section{Demographic data}

One hundred MSM were enrolled in this study. The majority of them were 18 - 25 years old (41.9\%), $87.6 \%$ were single, and $35.7 \%$ had a diploma degree. Almost a third of them (34.3\%) were unemployed.

\section{Sexual identity}

Sexual identity was the most frequently discussed topic by the participants, and could be considered the most important theme.

\section{Self-knowledge}

Half of the subjects identified their sexual identity as a girl or boy around the age of 3-4 years old. Since sexual maturity and stimuli are necessary for understanding sexual desires, perhaps there was no ambiguity about homosexuality at these ages. Although the participants had no role in determining their gender at birth, they believed that they have the right to choose it after birth.

\section{Self-belief}

The majority of participants stated that they must first accept their sexual identity and orientation, and then expect their family, other people, and community to accept them. 
On the other hand, some participants mentioned that they would not even tolerate an inappropriate attitude toward sexual minorities. him."

"If one person insults homosexual communities, I will stop

\section{Confusion}

Some participants were not certain about their sexual identity. They were sometimes confused about their sexual identity and orientation. In general, the subjects believed that MSM minorities have a problem with their sexual identity. This confusion was mostly attributed to others' behavior. However, some believed this confusion was due to differences between their conception and conventional definitions of homosexuality and trans-sexuality.

"Because of some issues and emotions, I still do not know whether I am a transsexual or homosexual..."

"My trance friends said that they are not satisfied with their body sexually and cannot tolerate it, but I do. I am 19 years old. Transsexuals are not satisfied with their bodies. Although I do not have such dissatisfaction, I still do not know whether I am a transsexual or a homosexual."

One of the participants answered a question regarding the tendency of some homosexuals to be trans.

"[the participant] Maybe they feel more secure in this way or because of sexual diversity, or even easier to get sex."

The incidence of some issues and conflicts in personal life was also stated to cause this uncertainty and confusion.

"In my opinion, the incidence of some problems like these conflicts could cause changes in the way of life, for example, a transsexual may not even be a transsexual at birth, or there are many people who simply recognized as men, but have some girlish behavior or vice versa. However, some accidents or issues in their life could change their way of thinking and bodily sexual perception toward being transsexual, so we cannot say that the person was a transsexual by birth".

\section{Impact of community insight and culture}

Most of the subjects believed that community could affect MSM's sexual identity and influence their choice to have a same-sex partner.

"Because of the community pressures, I think I can only have a relationship with the opposite sex... We are forced to become the same as other people... Once I decided to grow a beard to be less insulted, but it seemed it caused more attraction, attention, and more verbal abuse..."

\section{Role of religion}

Religion could play a vital role in the ambiguity of sexual identity.

"My religion is Shia and says that homosexuality is a grave sin and crime. It is forbidden. Now, if a Marjah Taqhlid announces it as a legal act, I will go back to my ordinary life."

\section{Sexual orientation}

The majority of participants were aware of their sexual orientation and felt satisfied. However, some of them still had doubts about their sexual orientation, and they stated some reasons.

"For many boys, it is easier to have sex with a boy, as the families are strict and prohibit premarital sex for girls, and actually the girls are not available."

Furthermore, one participant noted that they should refrain from suggestions from people with different sexual orientations to avoid this doubt.

"It depends on the person himself. He could refuse and not listen to the opinion and suggestion of a heterosexual person. Several weeks ago, I spoke to someone who was not aware of homosexual relationships. I explained that these relationships are the same as heterosexual relationships and maybe engage in more emotion."

Based on a participant's belief, sexual orientation was quite a personal matter.

"In my opinion, it does not concern the society what our sexual orientation is, and we allow others and even ourselves to involve in humanity neglected, inappropriate conversation regarding sexual orientation. However, this is a personal matter, and each person's sexual orientation only relates to himself. Therefore, it is more appropriate to consider humanity."

\section{Differences between sodomy and homosexuality}

All participants believed that homosexuality was different from sodomy. They also thought that increased restrictions led to an increase in sodomy. In homosexuality, a relationship is more important than sex, but in sodomy, sex is the priority. However, some disagreements among the participants were observed as well.

"Sodomy means that one person has sex with both same and opposite sex."

"No, this is bisexuality; sodomy is pederasty, not homosexuality."

"A pederast is someone who has wife and children, but if he has an opportunity, he will have sex with a boy or even a transsexual..."

"No, pederasty is not a bisexual... A married man who wants to have sex with a boy is pederasty."

\section{Bitter experience}

Regarding the role of bitter experiences in sexual orientation, most of the participants considered the presence of a bitter critical experience, regardless of a positive or negative effect. Generally, they stated that assault and misbehavior could confuse the sexual orientation.

"A homosexual who is bottom in sex with a heterosexual person; actually being abused by him, may change his attitude... depends on his decision, he can refuse a heterosexual suggestion." 
One participant said: "In my opinion, there is still no sense of sexual orientation in boys at the age of 11-12 years, everything has a standard. I think an 11-13 years old boy has no predominant sexual orientation yet. It does not relate to being top or bottom in a sex position. A boy who desires to have sex at the age of 11 or even 15 years had a problem in his childhood. Therefore, I think both persons involved in this sexual act are victims. They are both raped and abused, and I think it is wrong to have sex at an early age."

\section{Feeling guilty}

Abusive thoughts and feelings of guilt are common problems in sexual minorities and could affect sexual orientation. The majority of participants felt guilty when they became aware of their identity or sexual orientation for the first time, but this feeling disappeared after a while as the knowledge increased.

"At first, my thoughts of homosexuality were very bad, and I was feeling guilty. I denied myself and had many problems. I even thought of suicide. Later on, I concluded that if God has given me such emotions and tendency, then it could not be bad."

\section{Stigma and discrimination}

All the participants believed that society does not respect the privacy of MSM. Generally, discrimination could occur in different situations in the community. However, in this study, the most significant discrimination was related to sex/gender. Also, social and familial behavior discrimination was noted. Most importantly, the subjects mentioned that sometimes, they had to ignore their sexual orientation, harmonized with society, and even had anti-social behaviors, such as self-harm to escape the stigma and reduce discrimination assaults.

\section{Attitude of others toward their tendencies}

The participants were asked to explain their thoughts and beliefs after disclosure of their sexual orientation. The majority of them stated that their judgment changed after the disclosure of their sexual orientation; they felt comfortable with each other and could even be social friends.

The majority of participants noted that people often insult and ridicule them in the community and public places, and even physical assaults may occur. One participant was upset with people who take pictures or film them in public: "They do not hesitate to take pictures or film when seeing sexual minorities struggling with others for any reason, even after two months, they still recall and talk about it!"

Another participant said that stigma is present even among homosexuals.

"When we ask other homosexuals why they wear makeup, what can we expect from the heterosexuals?"

\section{Family and relative's attitude}

It appeared that stigma and discrimination are present in all families. Families do not allow children to play or spend time with friends of the opposite sex. They also do not allow them to choose a dress from the opposite gender, and the children should always dress according to their family's beliefs.

"I'd like to talk with my siblings and cousins about sex or marriage, but my family does not allow me. They told me if I talk to them, they will expel me from their group."

The majority of participants blamed the lack of social and family support of sexual minorities for their discrimination. One of the subjects blamed the self-hatred attitude in sexual minorities.

"I have seen masochistic and sadistic behaviors among sexual minorities, and even myself, they always harm themselves. Self-harm and self-injury are high in this group."

Some participants believed that a great amount of collaboration is required to remove the stigma from the community. One person stated: "Once, I decided to grow beards to be less annoyed."

Another indicated: "Boycotting by society, persecution by the community, and not even having an escape way, cause a high amount of emotional pressure and could lead to sudden decisions, which are often emotional, unreasonable, and risky."

\section{Family support}

The family has an undeniable role in several aspects of sexual life, such as training and treating children at young ages as a boy or girl, accepting and supporting their sexual identity and orientation. Most of the participants mentioned that the number of siblings in the family did not affect the behavior of parents and other members of the family. However, some people with different experiences mentioned this as an issue associated with poor training. Some believed that religion and family had significant roles as they could refuse to accept homosexuality.

The majority of participants said that their family would reject them if they chose a different sexual orientation and identity other than their families' wants. However, there was one participant who had a supportive family.

"My family accepts me and asks me not to allow anyone to insult me."

\section{Social and legal support}

The majority of participants believed that the legal and social supports for sexual minorities are not enough and do not even exist in some cases. One participant stated:

"The law does not consider any legal rights for sexual minorities and at best, it is considered as a mental illness or sexual disorder." One participant stated that he would like to start a family if he had legal and religious support.

\section{Partnership}

Most of the subjects believed the majority of MSM get to know each other through social media or at parties. 


\section{Place of meeting}

Most of the participants meet their partners at home. "We see each other at home... [maybe see] anyway, it could be everywhere: in the market, park, and zoo..."

\section{Frequency of partner's meeting}

It appeared that there was no certain time or place for meeting the partner.

"There is not a specific time; we see each other whenever we want... once or twice a week."

\section{HIV status disclosure and partner's selection}

Most of the participants noted that they choose their sexual partners based on HIV status; therefore, this seemed an important partnership criterion. HIV status of the majority was known to their partners.

"If he is HIV-positive, I will not have sex with him...". In contrast, "If he is HIV-positive but meets all my criteria, I would choose him."

\section{Age at the first sexual contact}

The majority of participants mentioned $20^{\text {th }}$ as their age for the first sexual contact.

"At the end of high school, when I was 17 or 18 years old, I had the first sexual contact, complete sex..."

"My first sexual contact was at the age of 22, with a friend who was introduced by another friend."

Some participants mentioned childhood sexual experiences, and they seemed to enjoy; they also seemed to enjoy the attention of the same sex and homosexuality.

\section{Type of sexual act}

The majority of participants stated that their sexual contact was soft (i.e., oral sex).

"We do everything except intercourse... I love soft..."

\section{Sexual dysfunction}

Some participants believed that their partners suffer from sexual dysfunctions.

"Yes, in my opinion, [my partner] has much sexual dysfunction."

\section{Long-term relationship and marriage}

Most of the participants believed that long-term homosexual relationships, especially marriage, are impossible in Iran due to the legal ban. However, a few believed that it could be possible if there were fidelity and commitment to the relationship. Sex was mentioned as the basis of most relations. It seems that there was no long-term emotional relationship and commitment, and it appeared that most MSM usually chooses a different partner from their sexual partner to express their emotions and satisfy their emotional needs.
One said: "The common causes of no commitment are quick progress of relationships toward having sex, which merely is due to sexual attractiveness with no thorough understanding of the partner's personality and emotions."

Another stated: "I do not believe in a relationship now... Relationships and friendships are moving to sex promptly... There must be a commitment between two partners."

Other causes were observed: "There are many causes, one irresponsible behavior of homosexuals and easy breakup. They often have many problems and do not want to involve themselves in their partner's problems, so it is easier to choose another partner."

"The secrecy between homosexual individuals is high because the families do not perceive them. We grow up in fear and anxiety because of our differences. We grow up with no models. Therefore, our relationships are without format and background (unclear relationship). Then, these factors can cause short-term relationships."

On the other hand, some people believed that they move from sole sex to more emotional and long-term relationships as they age. Other participants mentioned the fear of loneliness as a reason for the multiplicity of relationships. One also stated that he ignored himself to meet the needs of his partner.

"In my relationship, I reached a point where my partner's interests were only important to me, and I completely ignored myself."

\section{Normal and abnormal communications}

\section{Intimacy}

More than half of the participants believed that there are similarities in intimate relationships between heterosexuals and homosexuals. This was defined as a sympathetic relation without sex to satisfy emotional and psychological needs. On the other hand, they believed that friendship, ignorance, and quick demand for sexual experience among homosexuals were the consequences of no intimacy in an irregular relationship.

\section{Authority}

The majority of participants believed that there is no obligation in choosing a particular relationship. Values, selfesteem, and free will were essential in choosing a partner. They attributed the confusion in sexual identity, high-risk behaviors, low self-esteem, value of the partner's priorities, self-ignorance, multiple partnerships, and inappropriate use of cyberspace to the lack of authority.

"Most homosexuals are somehow being raped, no one asks them about using a condom, so they are somewhat surprised and forced into sexual contact, particularly at an earlier age."

\section{Personal and social satisfaction}

Most of the subjects recommended counseling and education as effective tools for raising the awareness of couples, 
the public, and governments regarding homosexual needs and social justice. The positive role of religious leaders in explaining homosexuality was also suggested to increase social satisfaction for homosexuals. They also thought selfknowledge/identity, body satisfaction, understanding the difference between homosexuality and sodomy, having a family with a healthy partner were critical factors in increasing personal satisfaction. They noted that older age could increase personal satisfaction because of the stability of values. Moreover, negative self-image, self-guilt, misjudgment, denial, suicidal thoughts, religious ban, homosexuals' tendency to be transsexuals, insecurity, the crime of homosexuality, diversity in sexual contacts, social pressure, inability to work and communicate with others, fear of arrest and lack of government support, were all mentioned as the reasons for dissatisfaction in homosexual relations.

\section{Trust}

The majority of participants believed respecting privacy, greater intimacy, and long-term relationships could increase the trust among homosexuals. In contrast, mistrust in counseling could simultaneously lead to physical and emotional harm. Furthermore, a suspicion might cause infidelity and, consequently, impulsive sexual behaviors. Some noted that it takes time, sometimes up to 4 months, to trust a partner.

\section{Mutual relationship}

Most of the participants mentioned commitment, partner recognition, socialization, knowledge of sexual behaviors, emotional support, engagement in both subjective (top) and objective (bottom) sexual positions, financial support, being a full gay, family values, and proper use of condom as the most significant factors in sustaining a mutual relationship.

Considering an abnormal mutual relation, most participants believed a gay man might get engaged in a homosexual or heterosexual relationship, or vice versa: "Girl loves gay man.” Moreover, worthlessness, spiritual damages, ignorance, emotional loss, divorce, unfaithfulness, self-involvement, reluctance to engage in a problematic relationship, fear and worries, lack of a life-time role model, lack of obligation in having the same sexual orientation as partner's, unimportance of partner's sexual orientation for many homosexuals, and sex priority to emotions, were all present in such relationships. Straights' desire to choose gays was due to a fewer problems that they may face in choosing a girl, and the higher excitement and more happiness that they experience. The choice of straights by gays was also due to their more availability and existence of sexual ideals, such as power and beauty.

There were also more masochistic and sadistic behaviors and a tendency to be annoyed in such relationships.

"I have seen a background of masochistic and sadistic behaviors in the sexual minorities and even myself. They always tend to be annoyed as well as self-injury."

\section{Honesty}

Most of the participants believed informing the families could lead to a permanent relationship. In contrast, secrecy (for example, marrying a gay with a woman as a cover for dealing with a family) or relation with another man besides the partner were instances of fraud in homosexual relationships.

"I know a homosexual who is about forty years old and has been engaged with a girl, but has a relationship with a man. His engagement is to talk down the family."

\section{Communication}

Regarding logical communication, the participants emphasized the right to participate in community activities with self-esteem and no violence (verbal and physical). The absence of stigma, public education regarding homosexuality, TV and social media, and family support were the critical factors in providing an appropriate platform for communicating with others in the community.

However, the majority of participants felt the negative attitude of society towards homosexuality. Disappointment in public opinion inherent in social rules, lack of civil rights for homosexuals, the family force for marriage, lack of supportive laws, people interference in personal life, insecure feeling in public, police disrespect in the persecution of homosexuals, psychological and social stigma, considering homosexuality as a psychological disorder in medical records, ineligibility for life insurance, lack of military services exemption for homosexuals, and difficulties in government employment, were some of the critical problems cited by homosexuals.

Based on some participants' statements, the city also has a significant role. In Tehran, a better society acquaintance by homosexual minority makes these problems less noticeable than in other cities. On the other hand, virtual homosexual dating networks, such as "Hornet", cannot function properly in improving homosexual relationships as the majority of members are straight. However, there were controversial conversations among the participants, and some considered a limited role in society.

"In my opinion, it does not concern the society in which sexual orientation we are engaged. In fact, it is just some people, even us, who, regardless of human rights, begin to discuss sexual orientation (homo-trance-heterosexual), while this is a personal matter. It relates to me; the sexual orientation of each person relates to himself, and it is best to think and speak about humanity instead."

\section{Respect}

The majority of participants mentioned mutual respect, lack of pederasty, lack of discrimination and sense of absurdity, and common understanding by others that were useful in permanent relationships. On the other hand, they mentioned that public rejection, disrespect, and potential scolding could lead to anxiety and even suicide among homosexuals. 


\section{Prevention of HIV transmission}

\section{Use of condom}

Some of the MSM in this study did not use condoms in sexual contact; however, they believed that they should reduce the risk of HIV infection. The main reason was dissatisfaction of the sexual partner. Other reasons included less sexual pleasure, lack of awareness regarding the importance of condom use, and neglecting the risk of STIs.

"Homosexuals usually do not like to use a condom... it must be used to prevent (transmission)."

On the other hand, several participants emphasized the feeling of power in using condoms.

\section{HIV self-testing}

One of the acceptable reasons for HIV self-testing was the ability to have the test without fear of society's feedback on the test result. They were motivated to do HIV testing given free access to the kits. HIV self-testing is an effective way of preventing HIV. The counseling and education provided, along with HIV testing, would address the concerns about illness disclosure and confidentiality. Furthermore, it could enhance public knowledge and awareness about the disease, which can help prevent and stop the spread of the disease.

It is necessary to build a culture and social capacity in this field. HIV self-testing should not be recommended or limited to a specific population; all people should be encouraged to use this test when necessary, and encourage others to do so. However, there is more need for information in some groups, like homosexuals; this need is more critical in males rather than in female population.

\section{Discussion}

This was the first study in Iran that described the attitudes, experiences, behaviors, and demands of MSM as a marginalized population susceptible to psycho-social problems, stigmatization, violence, and most importantly, HIV and STIs $[18,19,25]$. The evidence has shown that behavioral interventions are essential components of HIV prevention in MSM; therefore, characterization of this vulnerable group's socio-behavioral features is important in developing future interventions [26].

The MSM in the current study appeared to recognize their sexual identity as a boy in their childhood. However, they believed that sexual maturity and stimuli were necessary for understanding sexual desire. In a German study, some men were confused and unable to describe their sexual identity yet [27]. This confusion was attributed to people's behavior and attitude toward homosexuality by some participants. However, some believed this confusion was due to differences in the conventional definition of homosexuality and transsexuality with what they felt about themselves. Based on participants' statements, society's insight, culture, and religion also have important roles in Iranian MSM's sexual identity. This confusion about gender identity was also noticeable in a study from Nigeria, in which among 1,552 men, 103 participants reported their gender identity as 'other/unknown' [28]. It has been shown that gender non-conformity and confusion were associated with a higher prevalence of HIV and HIV-related risk behaviors [29]. These findings highlight the importance of gender identity as a factor affecting HIV treatment, care, and prevention programs.

Similar to a study from Nigeria [28], most of the participants in our study were aware of their sexual orientation. However, a number of them still had doubts about their sexual orientation. Unrecognizing the differences between sodomy and homosexuality, bitter experiences in the past, especially in childhood, and feeling guilty of their sexual identity and orientation, were mentioned as the influencing factors among our participants.

Stigma and discrimination could occur in various situations in society, especially regarding sex/gender-related matters. In addition, social and familial discriminative behaviors were noted in the present study. The participants reported anti-social behaviors, even self-harm, to avoid the stigma and reduce discrimination harm. In line with Friedman et al., stigma, prejudice, and discrimination create a stressful social environment, leading to a higher prevalence of psychological disorders and risk behaviors among MSM [30].

Concerning others' attitudes toward MSM's sexual orientation, they reported insults, violence, and even physical assaults in society. They also indicated that stigma is present even among MSM and in their family. Crowell et al. showed that some MSS (men who sell sex) and MSM avoid healthcare services and are afraid of being in public just because of the stigma of having sex with men [28].

As most participants noted, MSM chose their sex partners based on HIV status, and reported they were aware of their sexual partner's HIV status; forty-four percent said their partners did not tell them about their HIV status. Therefore, this may put them at a higher risk of acquiring HIV and STIs infection.

It appeared that the lack of legal, social, religious, and familial supports prevents long-term MSM relationships, like marriage. Consequently, multiple partnerships and infidelity were some of the factors that put sexual minorities at a greater risk for HIV and STIs.

In a study by Emmanuel et al., willingness to receive HIV prevention services, such as condom use, was $96.6 \%$ among 297 MSM [31]. However, similar to our study, most of the subjects mentioned that majority of MSM does not use condoms in sexual contact. Dissatisfaction and less sexual pleasure, lack of awareness regarding the importance of condom use, and negligence risk were the main reasons. Similar to a study in Germany, all men reported risky sexual behavior in the past year, where a condom was not used. More importantly, some participants mentioned HIV sero-positivity as a reason not to use a condom, which 
increasingly increases HIV infection risk. Furthermore, some reported having unprotected sex when their viral load was below the detection limit or their sexual partner had the same HIV serostatus [27]. Consistent with Nguyen et al. survey in Vietnam, less than half of the participants used condoms permanently in sexual relationships, magnifying the need for condom usage training programs among Iranian MSM [32-37].

\section{Conclusions}

Data regarding the prevalence of sexual activity in MSM is not available in many countries, including Iran. This marginalized population of society is more susceptible to psycho-social problems due to low sexual knowledge, and lack of community and legal supports. Moreover, the concurrent sexual partnerships, low condom use skills, and low HIV testing coverage pose a strong potential for HIV transmission in this vulnerable population. We recommend more endeavors to develop and establish specific prevention strategies and interventions aimed at both psychological and physical well-being of this vulnerable group in Iran, implementing the present study's knowledge.

\section{Conflict of interest}

The authors declare no conflict of interest.

\section{Acknowledgments}

Research reported in this publication was supported by Elite Researcher Grant Committee under award number [958639] from the National Institute for Medical Research Development (NIMAD), Tehran, Iran. The authors would like to thank all the staff and the subjects for their participation in the study.

\section{References}

1. Meyer IH. Prejudice, social stress, and mental health in lesbian, gay, and bisexual populations: conceptual issues and research evidence. Psychol Bull 2003; 129: 674-697.

2. Liu J, Yi Z, Zhao Y, Qu B, Zhu Y. The psychological health and associated factors of men who have sex with men in China: a crosssectional survey. PLoS One 2018; 13: e0197481.

3. Wong CF, Schrager SM, Holloway IW, Meyer IH, Kipke MD. Minority stress experiences and psychological well-being: the impact of support from and connection to social networks within the Los Angeles House and Ball communities. Prev Sci 2014; 15: 44-55.

4. Mehraeen E, Safdari R, SeyedAlinaghi SA, Mohammadzadeh N. Exploring and prioritization of mobile-based self-management strategies for HIV care. Infect Disord Drug Targets 2019; 19: 288-296.

5. Bostwick WB, Boyd CJ, Hughes TL, McCabe SE. Dimensions of sexual orientation and the prevalence of mood and anxiety disorders in the United States. Am J Public Health 2010; 100: 468-475.

6. Alvy LM, McKirnan DJ, Mansergh G, et al. Depression is associated with sexual risk among men who have sex with men, but is mediated by cognitive escape and self-efficacy. AIDS Behav 2011; 15: 1171-1179.
7. Niakan S, Mehraeen E, Noori T, Gozali E. Web and mobile based HIV prevention and intervention programs pros and cons - a review. Stud Health Technol Inform 2017; 236: 319-327.

8. Stall R, Mills TC, Williamson J, et al. Association of co-occurring psychosocial health problems and increased vulnerability to HIV/ AIDS among urban men who have sex with men. Am J Public Health 2003; 93: 939-942.

9. Mustanski B, Garofalo R, Herrick A, Donenberg G. Psychosocial health problems increase risk for HIV among urban young men who have sex with men: preliminary evidence of a syndemic in need of attention. Ann Behav Med 2007; 34: 37-45.

10. Darrow WW, Biersteker S, Geiss T, et al. Risky sexual behaviors associated with recreational drug use among men who have sex with men in an international resort area: challenges and opportunities. J Urban Health 2005; 82: 601-609.

11. Rajasingham R, Mimiaga MJ, White JM, Pinkston MM, Baden RP, Mitty JA. A systematic review of behavioral and treatment outcome studies among HIV-infected men who have sex with men who abuse crystal methamphetamine. AIDS Patient Care STDS 2012; 26: 36-52.

12. Santos GM, Coffin PO, Das M, et al. Dose-response associations between number and frequency of substance use and high-risk sexual behaviors among HIV-negative substance-using men who have sex with men (SUMSM) in San Francisco. J Acquir Immune Defic Syndr 2013; 63: 540-544.

13. Schwarcz S, Scheer S, McFarland W, et al. Prevalence of HIV infection and predictors of high-transmission sexual risk behaviors among men who have sex with men. Am J Public Health 2007; 97: 1067-1075.

14. Marcus U, Osamah H. Epidemiologie der HIV-Neuinfektion in den verschiedenen Risikogruppen. Bundesgesundheitsbl - Gesundheitsforsch - Gesundheitsschutz 2000 (Suppl 1) 43: S3-S8.

15. Zandmomen Z, Sardashti S, Firouzeh MM, et al. Addressing predictors of HIV related risk behaviors: demographic and psychosocial profile of Iranian patients. J Infect Public Health 2014; 7: 472-480.

16. Stall R, Friedman M, Catania JA. Interacting Epidemics And Gay Men's Health: A Theory Of Syndemic Production Among Urban Gay Men. In: Wolitski RJ, Stall R, Valdiserri RO (eds.). Unequal Opportunity: Health Disparities Affecting Gay and Bisexual Men in the United States. New York: Oxford University Press; 2008, p. 251-274.

17. Sander D. "Vulnerabilitätsfaktoren" im Kontext von HIV. In: Drewes J, Sweers H (eds.). Strukturelle Prävention und Gesundheitsförderung im Kontext von HIV. AIDS-Forum DAH, Bd. 57. Berlin: Deutsche Aids-Hilfe; 2006.

18. Chen G, Li Y, Zhang B, et al. Psychological characteristics in high-risk MSM in China. BMC Public Health 2012; 12: 58. DOI: https://doi.org/10.1186/1471-2458-12-58.

19. Feinstein BA, Bettin E, Swann G, et al. The influence of internalized stigma on the efficacy of an HIV prevention and relationship education program for young male couples. AIDS Behav 2018; 22 : 3847-3858.

20. Herek GM, Gillis JR, Cogan JC. Internalized stigma among sexual minority adults: insights from a social psychological perspective. Journal of Counseling Psychology 2009; 56: 32-43.

21. Mays VM, Cochran SD. Mental health correlates of perceived discrimination among lesbian, gay, and bisexual adults in the United States. Am J Public Health 2001; 91: 1869-1876.

22. Katz-Wise SL, Hyde JS. Victimization experiences of lesbian, gay, and bisexual individuals: a meta-analysis. J Sex Res 2012; 49: 142-167.

23. Mehraeen E, Safdari R, Mohammadzadeh N, Seyedalinaghi SA, Forootan S, Mohraz M. Mobile-based applications and functionalities for self-management of people living with HIV. Stud Health Technol Inform 2018; 248: 172-179.

24. Mehraeen E, Safdari R, Seyedalinaghi SA, Mohammadzadeh N, Arji G. Identifying and validating requirements of a mobile-based 
self-management system for people living with HIV. Stud Health Technol Inform 2018; 248: 140-147.

25. Jerome RC, Woods WJ, Moskowitz JT, Carrico AW. The psychological context of sexual compulsivity among men who have sex with men. AIDS Behav 2016; 20: 273-280.

26. McDaid LM, Hart GJ. Sexual risk behaviour for transmission of HIV in men who have sex with men: recent findings and potential interventions. Curr Opin HIV AIDS 2010; 5: 311-315.

27. Deimel D, Stöver H, Hößelbarth S, Dichtl A, Graf N, Gebhardt V. Drug use and health behaviour among German men who have sex with men: results of a qualitative, multi-centre study. Harm Reduct J 2016; $13: 36$.

28. Crowell TA, Keshinro B, Baral SD, et al. Stigma, access to healthcare, and HIV risks among men who sell sex to men in Nigeria. J Int AIDS Soc 2017; 20: 21489.

29. Jobson G, Tucker A, de Swardt G, et al. Gender identity and HIV risk among men who have sex with men in Cape Town, South Africa. AIDS Care 2018; 30: 1421-1425.

30. Friedman RC. Homosexuality, psychopathology, and suicidality. Arch Gen Psychiatry 1999; 56: 887-888.

31. Emmanuel G, Oluwatoyin Folayan M, Ochonye B, et al. HIV sexual risk behavior and preferred HIV prevention service outlet by men who have sex with men in Nigeria. BMC Health Serv Res 2019; 19: 261.

32. Nguyen TV, Van Khuu N, Nguyen PD, et al. Sociodemographic factors, sexual behaviors, and alcohol and recreational drug use associated with HIV among men who have sex with men in Southern Vietnam. AIDS Behav 2016; 20: 2357-2371.

33. Mohraz M, SeyedAlinaghi S, Asadollahi-Amin A, et al. Sociodemographic characteristics, HIV-related risk behaviors and HIV prevalence of vulnerable men in Tehran, Iran. Curr HIV Res 2021; 19: 352-357.

34. Farhoudi B, Ghalekhani N, Afsar Kazerooni P, et al. Cascade of care in people living with HIV in Iran in 2019; how far to reach UNAIDS/WHO targets. AIDS Care 2021. DOI: 10.1080/09540121. 2021.1944603 [Online ahead of print].

35. SeyedAlinaghi S, Taj L, Mazaheri-Tehrani E, et al. HIV in Iran: onset, responses, and future directions. AIDS 2021; 35: 529-542.

36. Najafi Z, Taj L, Dadras O, Ghadimi F, Moradmand B, SeyedAlinaghi S. Epidemiology of HIV in Iran. Curr HIV Res 2020; 18: 228-236.

37. Ghalehkhani N, Farhoudi B, Gouya MM, et al. The HIV treatment cascade in people living with HIV in Iran in 2014: Mixed-method study to measure losses and reasons. Int J STD AIDS 2019; 30: $1257-1264$. 